\title{
Non-invasive ventilation for exacerbations of respiratory failure in chronic obstructive pulmonary disease
}

\author{
J A Wedzicha \\ Respiratory Care Unit, London Chest Hospital, London, UK
}

Introductory articles

\section{Noninvasive ventilation for acute exacerbations of chronic obstructive pulmonary disease}

L Brochard, J Mancebo, M Wysocki, F Lofaso, G Conti, A Rauss, G Simonneau, S Benito, A Gasparetto, F Lemaire, D Isabey, A Harf

Background. In patients with acute exacerbations of chronic obstructive pulmonary disease, noninvasive ventilation may be used in an attempt to avoid endotracheal intubation and complications associated with mechanical ventilation. Methods. We conducted a prospective, randomized study comparing noninvasive pressure-support ventilation delivered through a face mask with standard treatment in patients admitted to five intensive care units over a 15 month period. Results. A total of 85 patients were recruited from a larger group of 275 patients with chronic obstructive pulmonary disease admitted to intensive care units in the same period. A total of $\mathbf{4 2}$ were randomly assigned to standard therapy and 43 to noninvasive ventilation. The two groups had similar clinical characteristics on admission to hospital. The use of noninvasive ventilation significantly reduced the need for endotracheal intubation (which was dictated by objective criteria): 11 of 43 patients (26 percent) in the noninvasive ventilation group were intubated, as compared with 31 of 42 (74 percent) in the standard treatment group $(P<0.001)$. In addition the frequency of complications was significantly lower in the noninvasive ventilation group (16 percent vs 48 percent, $P<0.001$ ), and the mean $( \pm S D$ ) hospital stay was significantly shorter for patients receiving noninvasive ventilation ( $23 \pm 17$ days vs $35 \pm 33$ days, $P=0.005)$. The inhospital mortality rate was also significantly reduced with noninvasive ventilation (4 of 43 patients, or 9 percent, in the noninvasive ventilation group died in the hospital, as compared with 12 of 42, or 29 percent, in the standard treatment group; $P=0.02)$. Conclusions. In selected patients with acute exacerbations of chronic obstructive pulmonary disease, noninvasive ventilation can reduce the need for endotracheal intubation, the length of the hospital stay, and the in-hospital mortality rate. (N Engl J Med 1995;333:817-22)

\section{Non-invasive mechanical ventilation in acute respiratory failure due to chronic obstructive pulmonary disease; correlates for success}

\author{
N Ambrosino, K Foglio, F, Rubini, E Clini, S Nava, M Vitacca
}

Background. Non-invasive mechanical ventilation is increasingly used in the treatment of acute respiratory failure in patients with chronic obstructive pulmonary disease (COPD). The aim of this study was to identify simple parameters to predict the success of this technique. Methods. Fifty nine episodes of acute respiratory failure in 47 patients with COPD treated with non-invasive mechanical ventilation were analysed, considering each one as successful (78\%) or unsuccessful $(22 \%)$ according to survival and to the need for endotracheal intubation. Results. Pneumonia was the cause of acute respiratory failure in $38 \%$ of the unsuccessful episodes but only in $9 \%$ of the successful ones. Success with non-invasive mechanical ventilation was associated with less severely abnormal baseline clinical and functional parameters, and with less severe levels of acidosis assessed during an initial trial of noninvasive mechanical ventilation. Conclusion. The severity of the episode of acute respiratory failure as assessed by clinical and functional compromise, and the level of acidosis and hypercapnia during an 
initial trial of non-invasive mechanical ventilation, have an influence on the likelihood of success with non-invasive mechanical ventilation and may prove to be useful in deciding whether to continue with this treatment. (Thorax 1995;50:755-7)

Patients with chronic obstructive pulmonary disease (COPD) are prone to exacerbations, especially with progression of their disease, which can lead to hypercapnic respiratory failure. Tracheal intubation and mechanical ventilation have been standard therapy for some patients with COPD who have deteriorating respiratory failure. The frequency of use of assisted ventilation in hypercapnic respiratory failure varies from $16 \%$ to $35 \%$ in reported studies, with an overall mortality of $19-29 \% .^{1}$ However, tracheal intubation has a number of complications including nosocomial pneumonia, laryngeal and tracheal injury, haemorrhage, and tracheal stenosis. Patients with COPD may be difficult to wean from ventilation, often require tracheostomies in view of the length of intubation, and thus have prolonged stays in the intensive care units.

\section{Advantages of non-invasive ventilation}

Non-invasive ventilatory techniques are therefore particularly useful for the management of these patients. Negative pressure devices have been available for many years but are relatively inefficient and cumbersome for use in acute respiratory failure and may predispose to upper airway obstruction. The introduction of noninvasive positive pressure ventilation (NIPPV) by nasal mask has thus been particularly welcome and the technique has now become the treatment of choice for domiciliary ventilatory support for patients with chest wall and neuromuscular disease. ${ }^{23}$ NIPPV has also been shown to improve arterial blood gas tensions, sleep quality, and quality of life in selected hypercapnic patients with stable COPD. ${ }^{4}$ The improvement in daytime blood gases with NIPPV in patients with stable COPD has been related to the reduction of nocturnal hypoventilation. Success has also been reported in using NIPPV for weaning patients from intubation and mechanical ventilation. ${ }^{56}$

A number of early small uncontrolled studies showed that it was also possible to use NIPPV in patients with acute exacerbations of respiratory failure due to COPD, with variable improvements being achieved in arterial blood gas tensions. ${ }^{7-15}$ With the use of NIPPV patient comfort is improved; there is no requirement for sedation and thus speech and swallowing are preserved. The technique can be used in a high dependency unit or general ward and intensive care is unnecessary. Patient cooperation is important in the application of NIPPV and excessive secretions can be troublesome as there is no direct access to the airway. The main advantage of the use of NIPPV is the avoidance of tracheal intubation and the ability to offer ventilatory support to patients with respiratory failure due to severe COPD who would be considered unsuitable for intubation.

\section{Pathophysiology of respiratory failure}

In patients with severe COPD the mechanical performance of the respiratory muscles is reduced. The airflow obstruction leads to hyperinflation with the respiratory muscles acting at a mechanical disadvantage and generating reduced inspiratory pressures. ${ }^{16}$ The load on the respiratory muscles is also increased by the presence of intrinsic positive end expiratory pressure (PEEP).${ }^{17}$ With an exacerbation of COPD the increase in airflow obstruction will further increase the load on the respiratory muscles and increase the work of breathing, precipitating respiratory failure. The resultant hypercapnia and acidosis will then reduce inspiratory muscle function, contributing to further deterioration in the respiratory function. ${ }^{18}$

Acidosis has been shown to be an important prognostic factor in survival from respiratory failure in COPD and thus early correction of acidosis is an essential goal of therapy. ${ }^{1}$ Studies have shown that NIPPV can produce improvements in $\mathrm{pH}$ relatively rapidly at one hour after instituting ventilation. ${ }^{19-21}$ This will allow time for other conventional treatments such as oxygen therapy, bronchodilators, steroids, and antibiotics to work, and thus reverse the progression of the respiratory failure and reduce mortality. A study using non-invasive pressure support ventilation in exacerbations of respiratory failure showed reductions in respiratory rate and in transdiaphragmatic activity with ventilation, with increases in tidal volume and minute ventilation. ${ }^{8}$ Thus NIPPV improves gas exchange, allows respiratory muscle rest, and reduces the respiratory muscle work in respiratory failure.

\section{Randomised controlled trials}

Following a number of uncontrolled trials, three randomised controlled trials have now been published on the use of non-invasive ventilation in exacerbations of respiratory failure in COPD. ${ }^{192122}$ These three studies reflect practice in various countries, with the first study coming from three centres in the $\mathrm{UK}^{19}$ the study by Brochard et al from five hospitals in France, Italy and Spain, ${ }^{21}$ and the third from the USA. ${ }^{22}$

The UK study by Bott et al showed that, with the use of NIPPV in exacerbations of respiratory failure, earlier correction of $\mathrm{pH}$ and reduction in breathlessness over the initial three days of ventilation can be achieved compared with a control group receiving standard treatment. ${ }^{19} \mathrm{~A}$ reduction in mortality rate was observed with the use of nasal ventilation, but only when patients who could not tolerate the ventilation were excluded from the analysis. This study differs from the other two trials in that relatively few patients in the standard treatment group were intubated, as is common practice in the UK. In the study by Kramer and colleagues ${ }^{22}$ almost all patients were offered intubation and ventilation on deterioration and the results showed a significant reduction in intubation rates with NIPPV from $67 \%$ in the standard group to $9 \%$ in the NIPPV group. No differences in mortality were observed in this study although relatively few patients with COPD were included and differences in medical practices between the countries where the studies were performed may be important. In the UK study most of the deaths occurred in patients who received no mechanical ventilation, but in the American study none of the patients died without some attempt at mechanical ventilation. 
Mean (SD) characteristics of patients with an acute exacerbation of COPD assigned to standard treatment or non-invasive ventilation (NIPPV) at admission and after one hour of treatment

\begin{tabular}{|c|c|c|c|c|c|c|}
\hline & \multicolumn{3}{|c|}{ Standard treatment } & \multicolumn{3}{|l|}{ NIPPV } \\
\hline & $\begin{array}{l}\text { Admission } \\
(n=42)\end{array}$ & $\begin{array}{l}1 \text { hour } \\
(n=39)\end{array}$ & $\begin{array}{l}p \\
\text { value }\end{array}$ & $\begin{array}{l}\text { Admission } \\
(n=43)\end{array}$ & $\begin{array}{l}1 \text { hour } \\
(n=42)\end{array}$ & $\begin{array}{l}p \\
\text { value }\end{array}$ \\
\hline $\begin{array}{l}\mathrm{PaO}_{2}(\mathrm{kPa}) \\
\mathrm{PaCO}_{2}(\mathrm{kPa}) \\
\text { pH } \\
\text { Respiratory rate (breaths/min) } \\
\text { Encephalopathy score }\end{array}$ & $\begin{array}{l}5 \cdot 2(1 \cdot 6) \\
8 \cdot 9(2 \cdot 1) \\
7 \cdot 28(0 \cdot 11) \\
33(7) \\
1.6(1 \cdot 2)\end{array}$ & $\begin{array}{l}7.7(3.2) \\
9.6(2.4) \\
7.26(0.11) \\
33(7) \\
1.9(1.3)\end{array}$ & $\begin{array}{l}0.01 \\
<0.005 \\
0.01 \\
\text { NS } \\
0.01\end{array}$ & $\begin{array}{l}5.5(1 \cdot 3) \\
9.3(1 \cdot 6) \\
7.27(0 \cdot 1) \\
35(7) \\
1.8(1 \cdot 3)\end{array}$ & $\begin{array}{l}8.8(2 \cdot 3) \\
9.1(1.7) \\
7.31(0.09) \\
25(8) \\
1.5(1.1)\end{array}$ & $\begin{array}{c}0.01 \\
N S \\
<0.001 \\
<0.001 \\
0.02\end{array}$ \\
\hline
\end{tabular}

There was no significant difference between the two groups at the time of admission. $p$ values refer to the comparison between data on admission and data at one hour in each group.

Modified from table 1 by Brochard et al. ${ }^{21}$

The study by Brochard et al again shows convincingly that, in patients with exacerbations of respiratory failure, the use of NIPPV with pressure support ventilation reduces the need for intubation. ${ }^{21}$ Mortality was significantly reduced with the use of NIPPV, from $29 \%$ in the standard group to $9 \%$ in those receiving NIPPV. Complications, which were specifically associated with the use of mechanical ventilation, were also reduced. The difference in mortality disappeared after adjustment for intubation, suggesting that the benefits with NIPPV result from fewer patients requiring intubation. This is also the first study to show that the length of stay in hospital is reduced with the use of NIPPV.

This study again confirmed that $\mathrm{pH}$ can be significantly improved at one hour with the use of nasal ventilation compared with standard treatment (table). The changes in $\mathrm{PaCO}_{2}$ in the NIPPV group overall were small and not significant at one hour, as has been found in other studies ${ }^{23}$ In both the NIPPV and control groups supplemental oxygen therapy was adjusted to maintain the arterial oxygen saturation above $90 \%$, although the actual oxygen flow rates used in this study are not stated. The relatively larger increase in the $\mathrm{PaO}_{2}$ with NIPPV may have been due to a greater inspired oxygen concentration delivered through a tighter fitting ventilation mask than through nasal prongs. The effects on the blood gas tensions were found to be greater if the analysis included only patients who were successfully treated with NIPPV (figure). This subgroup, in whom NIPPV was successfully implemented, showed significant reductions in encephalopathy scores and in respiratory rate as early as at one hour of ventilation, suggesting reduced work of breathing. These factors are important predictors of success. Patients with initially greater physiological impairment had a poorer outcome and this highlights the importance of early intervention with NIPPV. ${ }^{2021}$ Spirometric tests performed in survivors at three months showed no differences between the two study groups. However, information on blood gas tensions is not available before or after admission and it is not known whether the presence of chronic hypercapnia affected the outcome.

The authors emphasise that patient selection is important for the success of NIPPV. Among the inclusion criteria for the study were a $\mathrm{pH}$ below $7 \cdot 35$, respiratory rate of over 30 breaths $/ \mathrm{min}$, and $\mathrm{a}^{\mathrm{PaO}_{2}}$ on air of less than $6 \mathrm{kPa}$. Exclusion criteria for the study were numerous, with those patients requiring immediate intubation or having had a recent cardiac arrest being excluded from randomisation. Patients who had causes of respiratory failure other than COPD were also excluded, although some - for example, those with kyphoscoliosis - could have been treated successfully with NIPPV. Any patient who refused endotracheal intubation was excluded at the start of the study, together with any patient who required other specific treatment for decompensation - for example, myocardial infarction, pulmonary embolism, septic shock. As a result of the strict exclusion criteria, only 85 patients were recruited from an initial group of 275 patients admitted with acute on chronic respiratory failure and, of these, only $31(11 \cdot 3 \%)$ were eventually successfully treated with NIPPV without requiring intubation. This has implications for implementation of NIPPV into routine clinical practice as careful patient assessment will be required on admission.

A major economic advantage of non-invasive ventilation is that it can be used on general wards and thus there should be reduced costs from less requirement for intensive care and high dependency beds. The UK study ${ }^{19}$ was the only one where ventilation was administered on respiratory or general medical wards. Formal health economic analysis was not performed but, in the study by Kramer et al, ${ }^{22}$ costs were similar in the non-invasive and standard groups due to use of intensive care in both groups. The indications for intubation were different between the studies and further evaluation is required of cost effectiveness using common criteria for use of tracheal intubation.

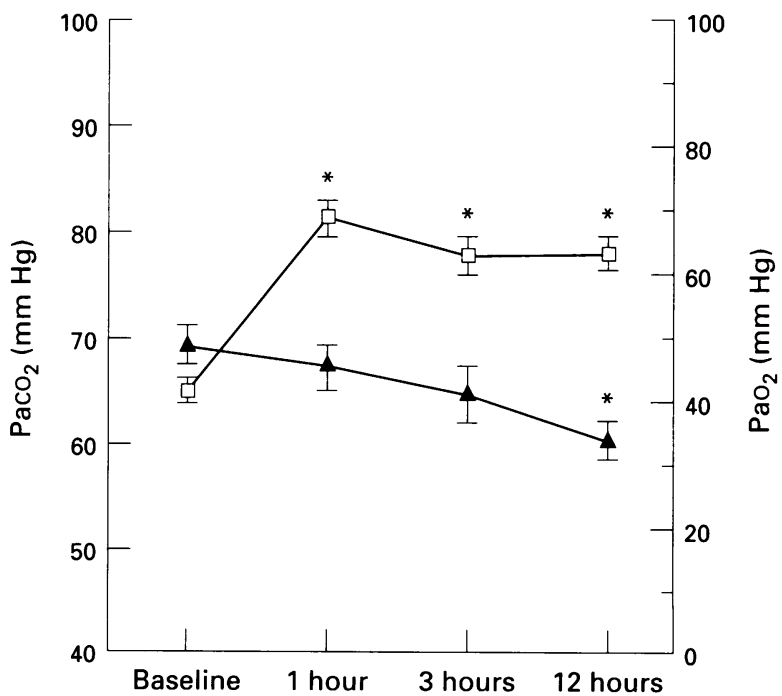

Mean (SE) values for the $\mathrm{PaO}_{2}$ ( $\square$ ) and $\mathrm{PaCO}_{2}$ (A) during the first 12 hours of ventilation in the 32 patients successfully treated with non-invasive ventilation $(7.5 \mathrm{~mm} \mathrm{Hg}=1 \mathrm{kPa})$. ${ }^{*} p<0.05$ compared with baseline values. Note that the $\mathrm{PaO}_{2}$ improved significantly after one hour in the ventilation group but the $\mathrm{PaCO}_{2}$ took up to 12 hours to show a significant fall. Reproduced with permission from Brochard et al. ${ }^{21}$ 


\section{Factors predicting outcome of NIPPV}

The aim of the study by Ambrosino and colleagues ${ }^{20}$ was to identify factors that could predict whether patients with COPD could be successfully treated with NIPPV and also to avoid unnecessary delay in intubation of those patients who deteriorate with the use of NIPPV. The study was retrospective in design and thus has limitations, especially with respect to standardisation of inspired oxygen flow rates, period of NIPPV use, and outcome measures. An important feature was that all patients were initially given a trial of non-invasive mechanical ventilation for up to two hours.

NIPPV was successfully established with respect to improvements in $\mathrm{pH}$, tachypnoea, and neurological status in $78 \%$ of the 59 episodes analysed. Pneumonia was the cause of respiratory failure in $38.5 \%$ of the unsuccessful episodes but in only $8.7 \%$ of those successfully treated, suggesting that pneumonia is an unfavourable prognostic factor for the use of NIPPV. The unsuccessful group were underweight, had a greater level of neurological deterioration, higher APACHE II scores, and a reduced level of compliance with the NIPPV. This group also had worse $\mathrm{PaCO}_{2}$ and $\mathrm{pH}$ levels at baseline before ventilation, again suggesting that NIPPV should be used early in the progression of respiratory failure for maximal effectiveness. Logistic regression analysis showed that only baseline $\mathrm{pH}$ had a significant independent predictive effect of eventual success with ventilation, which was greater when acidosis was less severe. The study also showed that the absolute level of $\mathrm{pH}$ and $\mathrm{PaCO}_{2}$ after the initial trial of NIPPV accurately identified those patients who could be successfully treated with non-invasive ventilation and such a trial could be useful in clinical practice.

\section{Choice of ventilator modes for NIPPV}

The three randomised controlled trials described used both volume cycled ${ }^{19}$ and pressure limited equipment ${ }^{2122}$ to deliver NIPPV. Ventilators for delivery of NIPPV have been specifically designed with sensitive triggers, which are required when ventilating patients with COPD with irregular breathing patterns and especially during episodes of respiratory failure. The presence of intrinsic PEEP further reduces the effective trigger sensitivity. ${ }^{17}$ Volume cycled ventilators deliver a fixed tidal volume and usually function in the assist/control mode, enabling them to provide breaths even if these are not triggered by the patient's own inspiratory effort. Pressure limited equipment cycles between preset inspiratory and expiratory pressures and can provide either pressure support ventilation, as used in the study by Brochard and colleagues, ${ }^{21}$ or an assist control mode or provide fully controlled ventilation. Pressure support ventilation has some advantages in patients with acute respiratory failure where the breathing pattern may be irregular. With pressure support ventilation all the breaths will be patient initiated, breath stacking will not occur, and initiation of ventilation and patient synchrony should theoretically be easier. However, in the presence of higher airway pressures, pressure limited ventilators may achieve suboptimal ventilation and thus volume cycled ventilators, which provide a fixed tidal volume, may be more useful. In practice, both volume and pressure cycled ventilators should be available and used depending on the particular clinical situation.

The expiratory pressure on pressure limited ventilators can be adjusted to provide positive end expiratory pressure that could be advantageous by reducing some of the effects of hyperinflation. Meecham Jones and colleagues $^{23}$ compared different modes of non-invasive ventilation after one hour of nasal ventilation in patients with acute exacerbations of COPD and found that pressure cycled ventilation, volume cycled ventilation, and continuous positive airway pressure (CPAP) could all improve oxygenation, but that the addition of expiratory positive airway pressure (EPAP) was poorly tolerated with persistent nasal mask leakage and produced no additional benefit. The effects on hypercapnia were more variable with CPAP having little effect as shown previously. ${ }^{2425}$ In this study some of the patients had very severe hypercapnia and significant falls in $\mathrm{PaCO}_{2}$ levels were not observed, in contrast to patients with lower baseline $\mathrm{PaCO}_{2}$ levels in whom reductions occurred. In severely affected COPD patients the ventilators used to deliver NIPPV may not be capable of generating sufficiently high pressures to reduce $\mathrm{PaCO}_{2}$ although the breathing pattern may be improved. Patients may also have difficulty in tolerating higher tidal volumes that can be administered with volume cycled ventilators. The increase in $\mathrm{PaO}_{2}$ with ventilation could further compromise respiratory drive and reduce the patient's active contribution to the ventilation. Thus, patients with severe hypercapnia and impaired respiratory drive may be difficult to treat effectively with non-invasive ventilation.

\section{Implementation of NIPPV}

There is now sufficient evidence that the use of NIPPV in patients with exacerbations of respiratory failure due to COPD is advantageous, resulting in reductions in rates of intubation and mortality. The criteria used in the study by Brochard et al are a useful guide for patient inclusion, and NIPPV should be considered when the $\mathrm{pH}$ is less than $7 \cdot 35$, respiratory rate above 30 breaths/ min, and $\mathrm{PaO}_{2}$ on air below $6 \mathrm{kPa}^{21}$ This means that NIPPV will be used at a much earlier stage in the course of respiratory failure than that at which intubation is normally considered. The aim of the earlier use of NIPPV is to prevent the development of more severe acidosis that has been shown to be a bad prognostic feature for recovery. ${ }^{20}$

The two introductory articles have both emphasised the importance of patient selection as being crucial for success with NIPPV. ${ }^{20} 21$ This implies careful assessment on admission and monitoring of the NIPPV, once instituted, so that patients who deteriorate are not denied the chance of intubation and ventilation. An initial trial of NIPPV for up to two hours is useful in predicting the eventual response. When severe acidosis and hypercapnia are present at the start of treatment, NIPPV may not be as efficient as formal mechanical ventilation, but it may stabilise the condition, prevent further acidosis and hypercapnia, and allow other therapies to be effective. ${ }^{23}$ Respiratory stimulants such as doxapram may be used in conjunction with NIPPV, especially when there is impairment of mental function and a reduced respiratory rate, although no controlled trials evaluating the role of respiratory stimulants in this situation have been reported. Doxapram has unpredictable actions in individual patients and significant side effects may occur. Overall, a relatively small proportion of patients who present with respiratory failure will be candidates for NIPPV, although eligibility will increase with wider experience of establishing NIPPV.

The application of NIPPV in episodes of acute respiratory failure requires considerable skill and patience, especially if the patient is confused, anxious, or uncooperative. As patients may prefer different ventilator 
LEARNING POINTS

\section{* Acidosis is an important prognostic factor for exacerbations of respiratory failure in COPD. * Early correction of acidosis is important in reducing mortality from exacerbations. * NIPPV can improve gas exchange and acidosis in exacerbations of respiratory failure. \\ * Rates of tracheal intubation, length of hospital stay, and mortality can be significantly reduced with NIPPV compared with standard therapy.}

* For maximal effectiveness NIPPV must be used early in the course of the respiratory failure.

modes, it is useful to have different types of ventilator available - either volume or pressure cycled. If NIPPV is administered on a respiratory or general medical ward, then staff covering the whole 24 hour period must be adequately trained in its use. Appropriate on-call cover with personnel trained in the application of NIPPV is required and will increase costs, although this should be offset by the reduced costs of not using intensive care. An earlier uncontrolled study suggested that NIPPV consumes considerable nursing time,${ }^{12}$ although other studies have shown that the rate of difficulty in caring for these patients is no more than that for standard therapy once staff are appropriately trained..$^{22}$ Reported studies have used NIPPV for between four and eight days from admission, ${ }^{192122}$ but the first 24 hours of NIPPV treatment is the most crucial for reversal of acidosis. The actual duration of NIPPV required for successful treatment is unknown, but a practical recommendation would be to use NIPPV as much as possible for the first 48 hours and then to continue ventilation overnight for approximately seven days or until improvement occurs. In the study by Brochard et $a l^{21}$ intubation in the control group occurred within the first 12 hours in $74 \%$ of the total patients intubated. Weaning difficulties have not been reported with the use of NIPPV.

Equipment for NIPPV should now be available in all hospitals where emergency cases with respiratory failure are admitted. The implementation of NIPPV as first line therapy for exacerbations of respiratory failure will correct acidosis earlier and reduce the frequency of intubation, associated complications of mechanical ventilation, and mortality. Ventilatory support is now available to patients who may not be considered suitable for intubation, although success in this specific group has not been formally evaluated in randomised controlled trials. Further research will be required to identify factors that predict success so that treatment can be implemented at the earliest opportunity after the development of respiratory failure in COPD.

1 Jeffrey AA, Warren PM, Flenley DC. Acute hypercapnic respiratory failure in patients with chronic obstructive lung disease: risk factors failure in patients with chronic obstructive lung disease: risk facto

2 Ellis RE, Bye BT, Bruderer JW, Sullivan CE. Treatment of respiratory failure during sleep in patients with neuromuscular disease. Positive pressure ventilation through a nose mask. Am Rev Respir Dis 1987, 135:148-52.

3 Carroll N, Branthwaite MA. Control of nocturnal hypoventilation by nasal intermittent positive pressure ventilation. Thorax 1988;43:34953.

4 Meecham Jones DJ, Paul EA, Jones PW, Wedzicha JA. Nasal pressure support ventilation plus oxygen compared to oxygen therapy alone in hypercapnic COPD. Am ₹ Respir Crit Care Med 1995;152:538-44.

5 Udwadia ZF, Santis GK, Steven MH, Simonds AK. Nasal ventilation to facilitate weaning in patients with chronic respiratory insufficiency. to facilitate weaning in

6 Restrick LJ, Scott AD, Ward EM, Feneck RO, Cornwell WE, Wedzicha JA. Nasal intermittent positive pressure ventilation in weaning intubated patients with chronic respiratory disease from assisted intermittent positive pressure ventilation. Respir Med 1993;87:199-204.

7 Meduri GU, Conoscenti CC, Menashe P, Nair S. Noninvasive face mask ventilation in patients with acute respiratory failure. Chest 1989 95:865-70.

8 Brochard L, Isabey D, Piquet J, Amaro P, Mancebo J, Messadi A, et al. Reversal of acute exacerbations of chronic obstructive lung disease by inspiratory assistance with a face mask. $N$ Engl $₹$ Med 1990;323: by inspirator.

9 Elliot MW, Steven MH, Phillips GD, Branthwaite MA. Non-invasive mechanical ventilation for acute respiratory failure. BMF 1990;300: 358-60.

10 Marino W. Intermittent volume cycled mechanical ventilation via nasal mask in patients with respiratory failure due to COPD. Chest 1991 99:618-4.

11 Pennock BE, Kaplan PD, Carlin BW, Sabangan JS, Magovern JA. Pressure support ventilation with a simplified ventilatory support system administered with a nasal mask in patients with respiratory failure. Chest 1991;100:1371-6.

12 Chevrolet JC, Jolliet P, Abajo B, Toussi A, Louis M. Nasal positive pressure ventilation in patients with acute respiratory failure: difficult and time consuming procedure for nurses. Chest 1991;100:775-82.

13 Benhamou D, Girault C, Faure C, Portier F, Muir JF. Nasal mask ventilation in acute respiratory failure: experience in elderly patients. Chest 1992;102:912-7.

14 Fernandez R, Blanch L, Valles J, Baigorri F, Artigas A. Pressure support ventilation via face mask in acute respiratory failure in hypercapnic COPD patients. Intensive Care Med 1993;19:456-61.

15 Hill NS. Noninvasive ventilation. Am Rev Respir Dis 1993;147:1050-5.

16 Macklem PT. Hyperinflation. Am Rev Respir Dis 1984;129:1-2.

17 Smith TC, Marini JJ. Impact of PEEP on lung mechanics and work of breathing in severe airflow obstruction. $f$ Appl Physiol 1988;65: 1488-99.

18 Juan G, Calverley P, Talamo C, Schnader J, Roussos C. Effect of carbon dioxide on diaphragmatic function in human beings. $N \mathrm{Engl} \mathcal{F} \mathrm{Med}$ 1984;310:874-9.

19 Bott J, Carroll MP, Conway JH, Keilty SEJ, Ward EM, Brown AM, et al. Randomised controlled trial of nasal ventilation in acute ventilatory failure due to chronic obstructive airways disease. Lancet 1993;341: 1555-7.

20 Ambrosino N, Fogio K, Rubini F, Clini E, Nava S, Vitacca M. Noninvasive mechanical ventilation in acute respiratory failure due to chronic obstructive pulmonary disease: correlates for success. Thorax 1995;50:755-7.

21 Brochard L, Mancero J, Wysocki M, Lofaso F, Conti G, Rauss A, et al. Noninvasive ventilation for acute exacerbations of chronic obstructive pulmonary disease. $N$ Engl f Med 1995;333:817-22.

22 Kramer N, Meyer TJ, Meharg J, Cece RD, Hill NS. Randomized prospective trial of noninvasive positive pressure ventilation in acute respiratory failure. Am ₹ Respir Crit Cam Med 1995:151:1799-806.

23 Meecham Jones DJ, Paul EA, Grahame-Clarke C, Wedzicha JA. Nasal ventilation in acute exacerbations of chronic obstructive pulmonary disease: effect of ventilator mode on arterial blood gas tensions. Thorax disease: effect of ven

24 Miro AM, Shivaram U, Hertig I. Continuous positive airway pressure in COPD patients in acute hypercapnic respiratory failure. Chest 1993 103:266-8

25 Goldberg P, Reissmann H, Maltais F, Ranieri M, Gottfried SB. Efficacy of noninvasive CPAP in COPD with acute respiratory failure. Eur Respir F 1995;8:1894-900. 